\title{
Una oportunidad para imaginar nuevas coartadas
}

\author{
Alberto Aziz Nassif
}

LETICIA REINA Y ELISA SERVÍN (coords.), 2002

\section{Crisis, reforma y revolución. México:}

\section{Historias de fin de siglo}

Taurus, Conaculta, INAH, México, 483 pp.

$\mathrm{U}$ na coartada, la similitud y las diferencias entre fechas fundantes de México. La animación de dos investigadoras y la realización de dos seminarios, uno en México y otro en Washington D.C., con la participación de once investigadores, produjeron Crisis, reforma y revolución. México: Historias de fin de siglo.

La coartada metodológica del libro se construye sobre la siguiente coincidencia histórica: la repetición de dos movimientos que cerraron el siglo XVIII y abrieron el XIX, en donde se

ALBERTO AZIZ NASSIF: CIESAS.

Desacatos, núm. 12, otoño 2003 , pp. 173-176. realizó el movimiento de Independencia de 1810; y el fin del XIX y el inicio del XX en donde estalló la Revolución de 1910. Esta oportunidad fue el pretexto para reflexionar sobre estos dos procesos históricos, y establecer preguntas sobre el final del siglo XX y el inicio del XXI. El libro está estructurado en tres partes: 1) la mirada comparativa, 2) la crisis, el liberalismo y la sociedad en el siglo XIX y, por último, 3) el cambio político y las transformaciones sociales en el siglo XX.

Cuando un país se acostumbra a vivir en crisis y a que sus grandes cambios se den mediante movimientos armados y violentos, resulta complicado entender por qué al final del siglo XX y el inicio del XXI puede haber una diferencia, aunque por lo pronto sólo podamos hacernos preguntas, como sucede cuando los trabajos de historia llevan la coartada metodológica al presente. ¿Se trata de coincidencias, de alguna ley histórica, quizá la continuación de procesos o de rupturas definidas? En cada texto hay hipótesis, datos, nuevas miradas, un esfuerzo

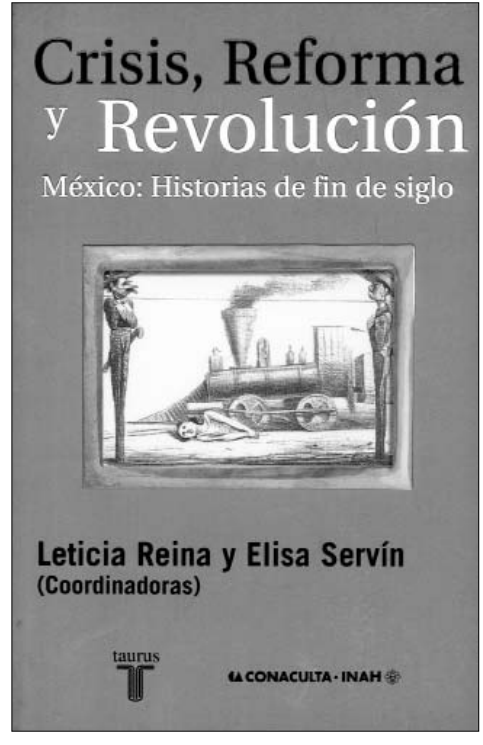


por salir de las interpretaciones tradicionales, tal vez un jalón más a planteamientos en los que cada autor ha trabajado durante años.

El libro está conformado por once ensayos independientes entre ellos y con un desarrollo original:

John Tutino hace un análisis interesante a partir de la tensión que generan la globalización y la autonomía de las comunidades locales, y a través de este mirador reconstruye la historia de la globalización borbónica, la Independencia y la autonomía de las comunidades. Más adelante establece el desarrollo del liberalismo y el gobierno de Díaz; luego viene el colapso del porfiriato y la Revolución; sigue el desarrollo del siglo XX, hasta llegar prácticamente a las preguntas actuales. Sin duda es un texto brillante de largo aliento que trata de comprender y vincular las estructuras económicas, las formas políticas y las identidades locales.

Alan Knigth escribe un ensayo para comparar y contrastar tres "coyunturas”, como él les llama: borbónica, porfiriana y priísta. A partir de un método riguroso el autor establece diferencias marcadas en el ámbito externo entre 1810 y 1910. La reconstrucción de una economía política lleva a Knigth a plantear una hipótesis interesante: la terquedad con que el régimen que termina tarda en irse. Incluso dice, hoy es un presupuesto a prueba, que el PRI ha evitado los errores políticos de los regímenes anteriores, el borbónico y el porfiriano, que se quedaron más de la cuenta. Me pregunto si esto es así, porque hasta el momento creo que el priísmo sigue presente, a pesar de que ha perdido significativos territorios de poder.

Friedrich Katz desarrolla el análisis de tres crisis externas que repercutieron de forma importante en la vida nacional: la guerra hispano-estadounidense, la Primera Guerra Mundial y la Segunda Guerra Mundial. Quizá la constante en esos tres momentos haya sido la complicada y conflictiva relación entre México y Estados Unidos; y al mismo tiempo, una situación interna completamente distinta: Porfirio Díaz estableció varias respuestas frente al conflicto entre España y Estados Unidos, soluciones en falso y contradictorias. Después, en plena Revolución, las tensiones entre el factor extranjero y la complicada situación de México que nos hizo, dice Katz, un país neutral hostil. Luego, en la Segunda Guerra, México fue un aliado abierto de Estados Unidos. Entre las dos grandes conflagraciones, el país enfrentó una situación interna completamente diferente, desde los años de la Revolución a la época de estabilidad. Hoy, frente al conflicto de Irak, se podría alargar la hipótesis para ver cómo se ha posicionado México en la ONU.

Eric Van Young se interna en la crisis del siglo XIX, pero desde el vínculo entre lo local y lo imperial. Después de una intensa indagación sobre el término de crisis, los tipos y modelos, se dedica al desarrollo de dos casos de motín, uno de 1785 en Cuautitlán y otro de 1810 en Atlacomulco. El primero fue una disputa violenta por un icono religioso. El segundo, un linchamiento a cuatro personas. La hipótesis es que lo local contiene el tejido de lo que después se generaliza con un movimiento más amplio; que en las estructuras locales están las disposiciones que van a permitir más adelante un movimiento de dimensiones mayores. El supuesto se podría aplicar a la época posrevolucionaria, en donde diversas experiencias regionales van conformando el Estado nacional, o los casos de luchas cívicas regionales que en los años ochenta del siglo XX, prefiguraron los movimientos democratizadores que llevaron al 2 de julio del año 2000. La pregunta con la que cierra el ensayo, sobre la identidad de una nacionalidad en las primeras décadas de la vida independiente, es muy sugerente para establecer nuevas hipótesis y romper mitos.

Antonio Annino hace un ensayo original para comprender el problema del liberalismo del XIX, pero desde la conformación de la ciudadanía. A través del análisis de dos temáticas, la soberanía y el territorio, elabora un mapa histórico de la llegada del liberalismo a estas tierras. Retoma las Cortes de Cádiz como primera experiencia liberal y establece el desfase entre el liberalismo y la Independencia. Más adelante indaga cómo se generaron los sincretismos de la política liberal con la nación indígena y luego con la cultura católica. Annino concluye que hubo un perfil de Jano Bifronte, dos caras del liberalismo, el de las elites, con la búsqueda de un modelo de desarrollo y estabilidad, y el de los pueblos que encontraron en el liberalismo recursos para defenderse del liberalismo que siempre fue anticomunitario. De nuevo, la polémica permanente hasta hoy entre 


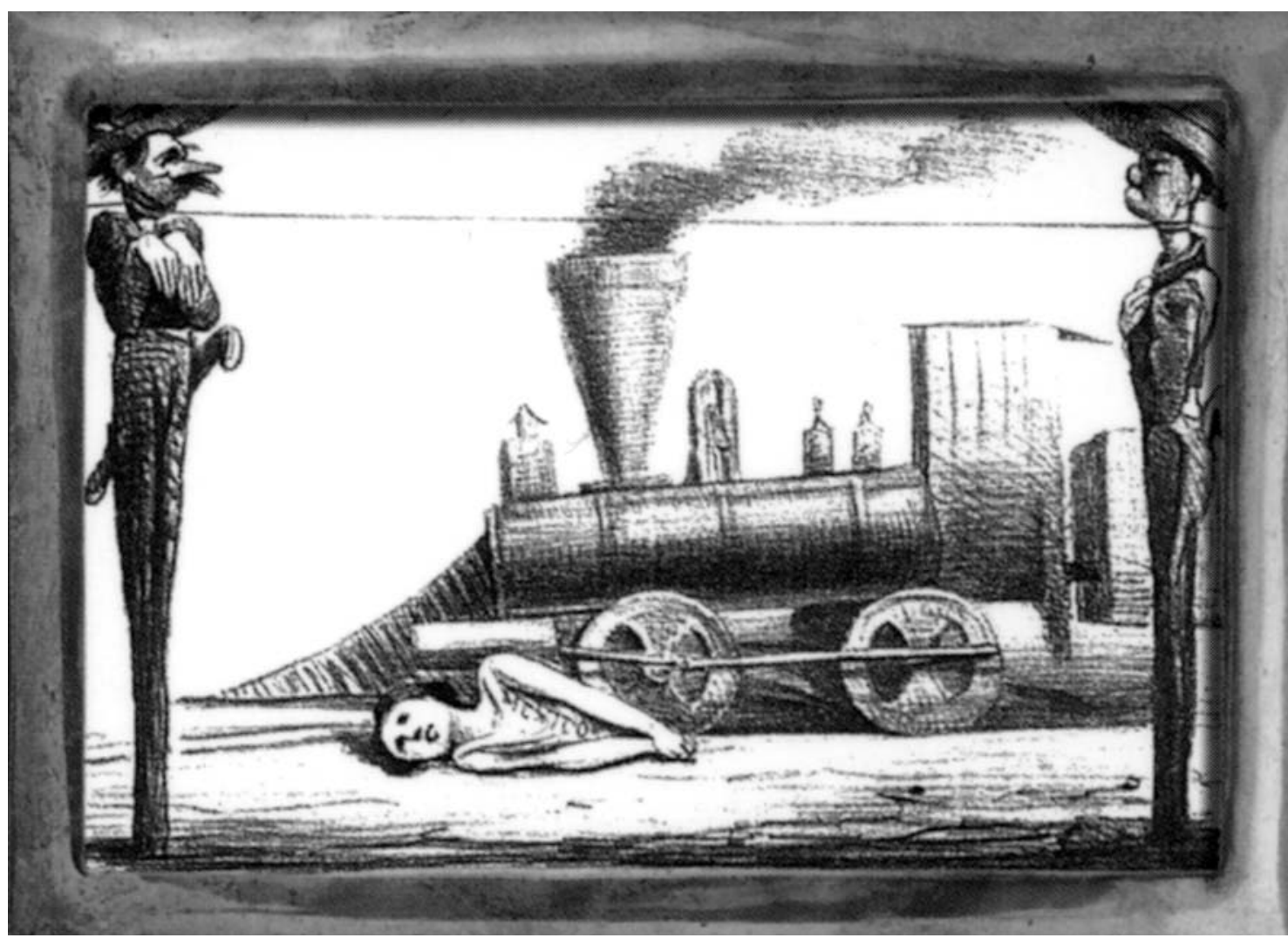

liberales y comunitaristas, pero en el siglo XIX.

Leticia Reina, coordinadora y autora, indaga sobre las elecciones locales en el cambio de los siglos y la cultura política de los pueblos indios. Establece el eje de la rebelión como una constante, $y$ al mismo tiempo, una metáfora, que significa en el texto el concepto de macehualización, con lo que se evoca la rebelión de algunos macehuales o gente común. El siglo XIX tuvo, dice Reina, dos formas de expresión: la municipalización y las elecciones. La pregunta de este artículo que hilvana los diferentes temas es: ¿cómo se articulan la lógica ciudadana, la cultura comunitaria de los pueblos indígenas, el autoritarismo del porfiriato y la detección de un índice creciente de conflictos agrarios que fueron pólvora para el movimiento revolucionario? La experiencia reciente cierra un ciclo y posiblemente abre otro. Queda otra pregunta pendiente: ¿qué pasará en el 2010? Por el momento, quizá sólo pueda ser una coartada para especular.

Francois-Xavier Guerra, un participante al que está dedicado el libro, el historiador francés del viejo régimen en nuestro país, y quien lamentablemente falleció antes de que el libro saliera publicado. Es por azar que las crisis tengan un siglo de diferencia. El análisis de Guerra es el de la política moderna, el liberalismo. El autor analiza tres problemas del siglo XIX: la soberanía, la representación política y la construcción de un Estado. Guerra hace una lectura balance del porfirismo, sin las cargas internas; reconoce sus aciertos y sus errores, lo cual todavía no forma parte del discurso político en México. En la otra parte hace una reflexión sobre el movimiento maderista y sobre Madero presidente, y cualquier semejanza con lo que tenemos hoy en día es algo más que pura coincidencia. El autor sostiene una defensa de la modernidad de Madero frente a versiones que lo han descalificado. También explica las razones de la Revolución en la perspectiva com- 
parada. Llaman la atención las explicaciones del autor sobre por qué fracasó el maderismo, es decir, un cauce de democracia en su doble promesa política y social. Creo, extrapolando la tesis del capítulo de Guerra, que las razones que ahora nos dificultan consolidar la democracia pueden ser similares a las del viejo régimen. Hay actores colectivos estructurados mayoritariamente, —bajo máscaras modernas-que mantienen vínculos antiguos, clientelas, dependencias, fidelidades, que entorpecen hoy, como lo hicieron después de 1910.

Lorenzo Meyer hace un análisis comparativo entre el liberalismo del siglo XIX y el neoliberalismo de finales del XX. Los temas son la naturaleza, los orígenes de cada liberalismo y el modo de funcionar. La caída del régitienen semejanzas y diferencias, la rigidez de una dictadura lo hizo vulnerable y terminó en la insurrección. En el otro caso, el hecho de abrir y reformar la economía y querer mantener el control autoritario de la vida política, lo debilitó hasta que perdió la presidencia, pero esta vez de forma pacífica. Se podría discutir si el actual gobierno se puede caracterizar como un neoliberalismo democrático, si el cardenismo fue un factor clave del rompimiento del viejo régimen o si los dos liberalismos se pueden comparar; pero en lo que coincido plenamente con el autor es en los tres temas de la agenda política del nuevo siglo

que plantea: consolidar la democracia, crear un Estado de derecho y dar una respuesta a la exigencia de justicia social.

Guillermo de la Peña hace un extenso recuento sobre los diversos movimientos sociales y las organizaciones de la sociedad civil de finales del siglo XX. Aquí podemos entender por qué el campo, que hoy dicen que no aguanta más, está como está. Hay un seguimiento de las organizaciones y movimientos campesinos. Más adelante se hace lo mismo, pero en el espacio del movimiento urbano popular, y finalmente, el resurgimiento de lo étnico a partir del zapatismo. Un mapa de movimientos y organizaciones ha desplegado una sociedad civil más amplia y vigorosa y rasgos notables de una cultura política distinta. A final de cuentas, ésta seguirá siendo una discusión polémica que necesitará investigaciones y datos duros, porque de la misma forma se pueden plantear presupuestos diferentes, incluso con los mismos datos.

Enrique Semo hace un recorrido de lo que han sido algunos de los actores y movimientos significativos de la izquierda mexicana en las últimas tres décadas del siglo XX. El ejercicio de hacer este mapa puede ser semejante a mirar un árbol cuyas ramas inferiores son más difusas y están cruzadas por un tronco autoritario que determinó y moduló a una izquierda poco democrática, desde el frente sindical hasta los partidos. La última parte es cono- cida, la izquierda realiza convergencias importantes y empieza a participar en un movimiento más amplio que toma fuerza con las ramas de la corriente democrática y posteriormente con el cardenismo perredista. Y unos años después, por otra parte, con el zapatismo, que logra colocar la cuestión étnica en la agenda nacional. La izquierda es un continente muy dispuesto a ser estudiado, y quizá hoy en día esa disposición se halla complicada de caracterizar, en un mundo de identidades locales que se enfrentan en un movimiento contestatario a la globalización. Además, la caída de los viejos paradigmas obliga a un trabajo creativo de recreación de una identidad muy fragmentada, que hoy necesita hacer esfuerzos para reconstruir una identidad y un proyecto, tema que está ausente en este trabajo pero que no está por demás desarrollar.

Al final, Elisa Servín, la otra coordinadora del libro, le da otra vuelta de tuerca al tema y nos ofrece un texto que hace un extenso recorrido por el régimen de la Revolución Mexicana, sus puntos culminantes, sus grietas, la decadencia, y finalmente, lo que la autora llama el desmontaje. Simbólicamente, para terminar, se hace una radiografía de las expectativas que generó la alternancia y la caída del viejo régimen, en donde destaca la diversidad de un país que en sus profundidades conviven "enclaves de modernidad" al mismo tiempo que "persistencias corporativas". 